\title{
Analogia da escravidão no Baixo Araguaia (MT) em pleno século XXI
}

\author{
Analogy of slavery in the Lower Araguaia (MT) in the 21st century
}

Susana Ferreira da Silva

Especialista em Educação do Campo (IFMT Campus Confresa). Professora da Educação Básica (SEDUC-MT).

E-mail: susyfds@hotmail.com

Vilson Ribeiro Magalhães

Especialista em Educação do Campo (IFMT Campus Confresa). Professor da Educação Básica (SEDUC-MT).

E-mail:vilsonrm01@hotmail.com

\author{
Mara Maria Dutra \\ Mestra em Ciência Ambientais (UNEMAT). \\ Professora na Educação Básica, Técnica e Tecnológica (IFMT Campus Barra do Garças). \\ E-mail: mara.dutra@bag.ifmt.edu.br
}

\begin{abstract}
Resumo: Desde a chegada dos portugueses no Brasil, a escravidão foi a força de trabalho mais utilizada pelos proprietários rurais. Com a abolição da escravatura, ainda no século XIX, não houve equiparação social tampouco cessou a exploração de pessoas menos favorecidas. Isso resultou em conflitos e resistências que permanecem até os dias atuais, e infelizmente parece que a força do mais forte ainda prevalece. Essa pesquisa teve como finalidade compreender de que forma ocorrem as relações de exploração do trabalho análogo ao escravo, bem como verificar se a falta de escolarização de crianças, jovens e adultos contribui para a ocorrência dessa situação na Região do Baixo Araguaia. Trata-se de uma pesquisa exploratória, de natureza básica e para que o objetivo fosse atingido, foi realizada uma revisão bibliográfica e documental. Verificou-se que o trabalho análogo ao escravo está presente no Brasil contemporâneo, bem como na região em estudo e que a maioria dos trabalhadores resgatados não tem escolaridade o que contribui ainda mais para as ocorrências. Espera-se que por meio da realização desse estudo seja possível denunciar e trazer à tona essa grave prática que ainda acontece em nosso meio. Além disso, o estudo vem somar-se às lutas de vários indivíduos, geralmente reprimidos, que por décadas tem buscado modificar a situação de trabalhadores na região do Baixo Araguaia, localizada no Estado de Mato Grosso.
\end{abstract}

Palavras-chave: Educação; Escravidão; Exploração; Latifúndio; Trabalhador.

Abstract: Since the arrival of the Portuguese in Brazil, slavery has been the work force most used by rural landowners. With the abolition of slavery, still in the nineteenth century, there was no social assimilation, nor did the exploitation of less privileged persons cease. This has resulted in conflicts and resistances that remain to this day, and unfortunately it seems that the strength of the strongest still prevails. The purpose of this research was to understand how the relationships of exploitation of work analogous to the slave occur, as well as to verify if the lack of schooling of children, youth and adults contributes to the occurrence of this situation in the Baixo Araguaia Region. It is an exploratory research, of a basic nature and in order to achieve the objective, a bibliographical and documentary review was carried out. It was verified that the work analogous to the slave is present in contemporary Brazil, as well as in the region under study and it is proven that the majority of the rescued workers do not have schooling which contributes even more to the occurrences. It is hoped that by conducting this study it will 
be possible to denounce and bring to light the grave practice that still exists in our milieu. In addition, the study is in addition to the struggles of several individuals, generally repressed, who for decades have sought to change the situation of workers in the region of Baixo Araguaia, located in the State of Mato Grosso.

Keywords: Education; Slavery; Exploration; Latifundio; Worker.

\section{Introdução}

A escravidão no Brasil tem raízes profundas e históricas. Seu início no país pode ser considerado desde o século XVI, com a chegada dos colonizadores portugueses. Se formos analisar a região Centro-Oeste do país verifica-se que essa prática ainda não foi superada. Muitos são os casos de trabalho análogo ao trabalho escravo em Mato Grosso, marcado pela desigualdade social, analfabetismo, desrespeito às leis trabalhistas e grandes investimentos no agronegócio.

Esse estudo se propõe em ser voz a muitos trabalhadores que se calam ou são calados por uma política pública voltada ao latifúndio, e dar continuidade em debates e pesquisas pode ser uma pequena semente para a mudança futura quanto ao trabalho análogo ao escravo no Brasil. O estudo se justifica, pois, mesmo com o aumento da mobilização da sociedade, apoio às campanhas, às denúncias e tantos depoimentos ainda estamos longe de quebrar o ciclo da escravização. Entretanto, de acordo com Sakamoto (2015) novos passos são indispensáveis para construir alternativas reais na vida dos trabalhadores brasileiros.

Nesse sentido, dentre os vários pesquisadores sobre o trabalho análogo ao escravo queremos destacar o trabalho de Souza (2016) e Le Breton (2002) que em seus estudos abordam a questão do trabalho escravo contemporâneo e trazem dados sobre a Região do Baixo Araguaia. Dessa forma, ao se propor verificar a ocorrência de trabalho análogo ao escravo na região do Baixo Araguaia, o estudo se apoia em uma pesquisa exploratória, que segundo Gil (2010, p. 41) "têm como objetivo proporcionar maior familiaridade com o problema, com vistas a torná-lo mais explícito". É de natureza básica, pois seus conhecimentos não possuem aplicação prática prevista.

Para que o objetivo supracitado fosse atingido, foi realizado uma revisão bibliográfica e documental com análise de documentos, textos, artigos, teses, obras literárias, jornais, periódicos e revistas digitais. A maioria dos dados foi coletada no "Registro" da Prelazia de São Félix do Araguaia-MT.

Trata-se de uma pesquisa qualitativa, que se propõe a investigar, no acervo da Prelazia, histórias de vidas no sentido de compreender de que forma ocorrem as relações de exploração 
do trabalho análogo ao escravo, bem como verificar se a falta de escolarização de crianças, jovens e adultos contribui com a ocorrência dessa situação na região do Baixo Araguaia, para tanto utilizamos como recorte temporal o século XXI.

Os dados e discussões obtidas com a pesquisa seguem apresentados em cinco seções. Na primeira seção o poder das diferenças quanto à escravidão e a liberdade das pessoas são abordados. A segunda apresenta a exclusão de uma parte da sociedade marginalizada e também explorada pelo processo capitalista com uma tradição oligárquica. Na terceira são expostos alguns fatores que levam o leitor a uma compreensão dos elementos que ferem a dignidade dos cidadãos, degradando-os, nessa seção percebe-se a importância em discutir, buscar registros, dialogar, questionar e analisar o trabalho análogo ao escravo. Já a quarta seção apresenta a falta de oportunidade de emprego e a desqualificação da mão de obra que pode ser considerada como elemento fundamental à prática do trabalho análogo ao escravo. A quinta e última seção apresenta as considerações sobre o estudo, bem como as constatações e aprendizados proporcionados pelo estudo.

\section{0 poder das diferenças: escravidão e liberdade}

A escravidão no Brasil teve início com a chegada dos portugueses e a implantação de uma ação colonizadora de exploração. Essa por sua vez, propiciou um processo de regime ao qual o trabalho escravo era o mais acessível para agregar forças na aquisição da nova terra conquistada, e dela, retirarem as mercadorias tão valorizadas no mercado europeu. Obter escravos significava a produção de bens no qual fortaleceria os ideais mercantilistas dessa época. Visto isso, pensemos no conceito 'escravo' elucidado por Cardoso (1998, p.2),

O escravo seria, então, aquele tipo de trabalhador que, no interior do processo de produção, não estaria apenas apartado do controle dos meios produtivos (característica que compartilha com outros tipos de trabalhadores, inclusive o assalariado), mas também privado do controle de seu próprio esforço produtivo. Vale dizer, é marcado pela ausência de soberania quanto à sua inserção no processo que garante a subsistência material, quanto à sua posição produtiva elementar.

Poderia o 'eu' fazer-se escravo o 'outro', aqui tomando uma postura étnica, branco, negro, indígena. Essa representação do ser escravo pode ser visualizada nos sistemas simbólicos fortalecidos pela raça branca, nesse caso, os portugueses que conquistaram colônias e por seu bel prazer estipularam dos nativos a sua força de exploração.

Neste contexto, a exclusão que pode ser vista numa ótica 'etnicorracial' discorre como um formato de marcação das diferenças, em que os "sistemas de classificação dão ordem à vida 
social, sendo afirmados nas falas e nos rituais" (SILVA; HALL; WOORDWARD, 2000, p. 40). Com isso, a diferença pode se apresentar por meio da exclusão ou da marginalização de sujeitos, esse enquadra em sistemas classificatórios.

Ressalta então, que o processo de escravidão no Brasil negativa o africano e o índio de sua cultura e os conduz a condição de escravo, identidade imposta pela Metrópole portuguesa no qual Silva, Halle Woodward (2000, p. 110) observam que as identidades podem ser "construídas no interior do jogo de poder e da exclusão".

Pautadas nesse jogo de poder, a mão de obra no Brasil Colônia foi suprida por nativos denominados pelos europeus como indígenas. Porém, a legislação colonial proibia a escravidão destes povos, sendo permitida apenas em casos excepcionais. No entanto, a existência de uma lei que protegia os nativos do trabalho escravo não foi suficiente para dar-lhes direitos de escolha. Levados a extração das riquezas naturais, os indígenas que resistiram à escravidão eram mortos ou fugiam do litoral brasileiro rumo ao centro e norte do país, entrando em conflito com outros grupos étnicos que já habitavam estas regiões (FAUSTO, 2002).

Tornando-se moradores no Brasil colonial, os portugueses ampliaram seus mercados de produção atribuindo a construção de engenhos de açúcar, um comércio rentável aos cofres lusitanos. Desse modo, os portugueses intensificaram o processo de exploração do território e com a cultura da cana-de-açúcar iniciaram a utilização de mão-de-obra escrava vinda das colônias portuguesas na África (COTRIM, 1998).

Porém, mesmo existindo a intensa migração de africanos para o Brasil- os quais eram capturados e transportados para a nova colônia portuguesa-a quantidade era insuficiente para prover os trabalhos braçais nas lavouras. Para Rodrigues (2010, p.20), os negros "não eram mais do que simples máquinas ou instrumentos de trabalho" (p. 21, 2010).

Surgiu como problema brasileiro quando, faltando o índio que sucumbia ou era protegido pelos jesuítas, e começando a escassear os braços para a lavoura e, mais tarde, para o trabalho das minas, se criou um comércio de escravos direto, entre a nova Colônia e a África. O grande tráfico iniciou-se pouco menos de uns 50 anos após a descoberta do Brasil com alguns navios, por particulares, enviados à África (RODRIGUES, 2010, p. 20).

O escravo africano atribuía muitas despesas e seu preço não o tornava uma mão de obra acessível a todos os portugueses. Havia diferentes níveis econômicos entre os portugueses das Capitanias Hereditárias. As capitanias localizadas na região nordeste possuíam melhores condições de compra do estrangeiro africano. Justificando essas disparidades econômicas, a segunda metade do século XVII apresenta as primeiras expedições paulistas que tem como uma de suas finalidades a captura de indígenas para sanar a necessidade de mão de obra barata. 
Segundo Neto (2015, p.12) “a história das expedições sertanistas está ligada, de forma indissociável, à pobreza do planalto da capitania de Martim Afonso". De acordo com Volpato (1985), as motivações paulistas surgiram pois:

O movimento bandeirantista surgiu da necessidade de mão-de-obra dos habitantes do planalto piratiningano. Sem condições de importar os escravos africanos que o comércio europeu colocava-lhes à disposição nos portos coloniais, utilizavam a força de trabalho indígena. As condições específicas da sociedade do planalto não lhes permitiam consumir um dos mais caros e mais absorvidos produtos, mercantilizado pela exploração do comércio colonial - o escravo africano (VOLPATO, 1985, p. 45).

Portanto, as expedições paulistas adentraram a região dos rios Araguaia e Tocantins em busca de trabalhadores indígenas para a escravidão (FAUSTO, 1999), e, com o processo aurífero que se concretiza nos séculos XVII e XVIII, a colonização dos 'sertões' aumentou o contato dos brancos aos indígenas, o que provocou o extermínio de várias etnias nativas. Verifica-se na história indígena brasileira que esses povos foram deixados a mercê de sua sorte, observando que ao debater a abolição o índio não estava em discussão, devido ser entendido como escravo apenas os africanos e seus descendentes. Isso é um aspecto relevante que reprime, ainda hoje, a luta indígena pela preservação de seus direitos a manutenção de suas propriedades e cultura.

Com o passar dos anos, décadas e séculos, as políticas mundiais foram tomando rumos diferenciados. Vários países sancionaram leis que erradicaram o trabalho escravo. O Brasil foi o último país do mundo ocidental a abolir a escravidão (MOTA; BRAICK, 1997). Mesmo com a abolição a estratificação social da sociedade separava os pobres miseráveis dos ricos que eram e ainda constituem minoria, e privilegiados por uma barreira de "indiferenças" e preconceitos, onde tudo era concedido e permitido.

Nesse sentido, Darcy Ribeiro (1995 p. 120) ao escrever sobre as heranças das ações brasileiras afirma que: "Ainda hoje, em tanta autoridade brasileira predisposta a torturar, seviciar e machucar os pobres", apontando assim que ainda somos uma terra de escravos e senhores de escravos.

Contudo, a abolição da escravatura no Brasil teve um longo processo anterior de violência e negação entre seus intérpretes, a metrópole portuguesa, o império, a sociedade, os escravocratas, os escravos e os abolicionistas. Os africanos foram os primeiros a rebelar-se contra a escravidão, em resistência aos seus senhores brancos realizavam fugas constantes para os quilombos. Já no século XIX algumas revoltas como a Cabanagem (1835) e a Balaiada (1838) tinham negros, mulatos e escravos como participantes e um dos motivos era sua 
libertação. Desse contexto, algumas garantias foram exibidas ao escravo como o direito a sua própria compra, a Lei Eusébio de Queirós (1850), a Lei do Ventre Livre (1871) e a Lei dos Sexagenários (1884) (CARDOSO, 1998).

Mudanças nas leis internacionais também favoreceram ao movimento abolicionista, como podemos expor a supressão ao tráfico com a criação em 1787 de frentes na Inglaterra que emanava uma sociedade na luta contra a escravidão e a partir de 1820, os ingleses começam a patrulhar os mares contra o tráfico negreiro, e também, os ideais franceses de liberdade, igualdade e fraternidade que soava pela terra brasilis.

Desse modo, Alonso (2014, p. 134) revela,

O abolicionismo brasileiro aconteceu no tempo em que se inventava o próprio fenômeno "movimento social". Contudo, a variedade de estratégias, a estruturação em rede, as alianças internacionais denotam sua modernidade. São semelhantes às de seus primos do século XXI. Soa contemporâneo também porque restam no presente heranças suas. O impacto de um movimento transcende o instante de sua ocorrência. Perdura difuso no longo prazo, encarnado nas práticas políticas de um país. Entender o abolicionismo, seus antagonistas e o andamento do processo político da Abolição importam porque o fim da escravidão dividiu águas na história do Brasil, mas também porque a natureza de seu remate reverbera ainda nas formas contemporâneas da desigualdade.

O regime escravista consentiu aos agora 'ex-escravos' a condição de liberdade sem autonomia, não podendo escolher melhorias básicas como moradia, saúde, educação, etc.; seu legado foi à criminalização e preconceito a sua negritude. Após a aprovação da Lei Áurea, a proporção de alforriados aumentou e também sua marginalização social, se misturando aos brancos pobres e miseráveis nas vilas e cidades (CARDOSO, 1998).

Para Monteiro (2012, p. 360),

Procedendo-se à interpretação literal e teleológica da norma, extrai-se que a finalidade da Lei Áurea foi a imediata extinção da escravidão no Brasil. A partir de então, uma a uma as portas das senzalas foram sendo abertas e os negros puderam irromper, pela primeira vez, os limites das cercas das propriedades de seus senhores, como forma de concretizar os ditames literais da lei. No entanto, se no primeiro momento a Lei Áurea significou a libertação dos escravos do jugo dos seus senhores, no momento seguinte, condenou aqueles a viverem como vítimas do sistema, uma vez que se encontravam livres, sem, contudo, possuírem estudo, documentos, dinheiro, moradia, emprego, escola e nenhuma outra espécie de assistência social proporcionada pelo Estado.

Sem trabalho e lugar para morar, os alforria dos migraram para outras regiões em busca de sustento para suas famílias, levando-os a aceitarem vários tipos de trabalho e enfrentarem diferentes formas de exploração e violência (SOUZA, 2016). Já o pesquisador Monteiro (2012, 
p. 362) esclarece que "a tão almejada Lei Áurea decretou a liberdade de direito, sem, contudo, concretizá-la de fato, dando aos negros, num primeiro plano, e a toda a sociedade, em segundo, a falsa promessa de liberdade".

Pensemos liberdade como expressa Bobbio (2000, p. 54):

Essa última categoria de direito é chamada de direitos econômicos e sociais, cujo escopo, ademais de reafirmar sua dignidade, é concorrer para o livre desenvolvimento da sua personalidade. Por sua vez, a 'liberdade para' atribui ao indivíduo não só a faculdade, mas também o poder de fazer. Se houvesse apenas as liberdades negativas, todos seriam igualmente livres, mas nem todos teriam igual poder. Para equiparar os indivíduos, quando os reconhecemos como pessoas sociais, inclusive no poder, é necessário que sejam reconhecidos outros direitos, como os direitos sociais, os quais devem pôr cada indivíduo em condição de dispor do poder de fazer aquilo que é livre para fazer.

Vimos que o ato da Abolição da Escravatura pode ser considerado uma negação ao direito social do indivíduo, libertar, alforriar, soltar, deixar o 'ex-escravo' o direito de sair do domínio do seu senhor não representou, de maneira nenhuma, a igualdade de sujeitos, o abismo socioeconômico iria trazer aos abolidos uma nova forma de luta, a luta pela sobrevivência. Não houve tentativas de equiparação social no Brasil da lei assinada pela princesa Isabel e isso proporcionou um abismo cheio de mazelas que ainda reflete na sociedade atual.

\section{0 poder das diferenças: exclusão e exploração}

Se o propósito da Abolição da Escravatura foi de libertar, não houve, portanto, garantias por parte do Estado a igualdades de oportunidades entre brancos e negros. Nesse sentido, cabe citar a Lei $\mathrm{n}^{\mathrm{o}} 601$ de 18 de setembro de 1850, conhecida mais como de Lei de Terras, que promoveu a expansão dos latifúndios que já existiam e excluiu as oportunidades para aqueles que viam na terra sua única fonte de trabalho e sobrevivência (OLIVEIRA, 2007). Assim, os imigrantes, os pequenos proprietários, os negros livres, viram-se ainda sujeitos ao poder dos latifundiários.

Em 1913, o decreto $\mathrm{n}^{\mathrm{o}} 10.105$ reconheceu o fracasso da Lei de Terras de 1850, pois tornou-se comum a invasão dos grandes proprietários às terras públicas além de ser uma forma de injustiça social (OLIVEIRA, 2007). Infelizmente, esse decreto não trouxe grandes mudanças, pois o apoio do Estado Federal aos grupos regionais dominantes, a chamada, "política dos governadores" continuou da mesma forma.

O século XX é marcado pelo estímulo migratório no Brasil. Um dos fatos significativos foi a Marcha para o Oeste, programa criado por Getúlio Vargas em 1937 e que cresce as migrações para as regiões interioranas pouco habitadas. A migração nada mais era que a 
tentativa de melhoria de vida de famílias que caminham ao oeste brasileiro em busca de riquezas. No entanto, encontram nos sertões a falta de infraestrutura e o poderio dos latifundiários (RUA, 1997).

Os estados de Goiás, Paraná e Mato Grosso foram as localidades habitadas, e, anos mais tarde, o Pará e áreas denominadas Amazônia Legal. Segundo Pessoa (1999, p.47),

[...] as verdadeiras razões da Marcha para o Oeste, especialmente quanto à criação das colônias agrícolas, eram a abertura de frentes fornecedoras de produtos alimentícios mais baratos para os centros urbanos emergentes e a contenção de conflitos sociais já verificados em outras regiões do país, direcionando os excedentes populacionais para os vazios demográficos existentes.

Esses movimentos migratórios ocasionaram invasões e choques entre posseiros, latifundiários e grileiros, como é escrito por Dourado (2014, p. 103,),

A emergência de organizações e conflitos no campo, como as Ligas Camponesas, a Revolta de Porecatu e a própria Luta de Trombas e Formoso, se deve à expansão e à consolidação capitalista no campo, que atingiu, sobremaneira, camponeses e posseiros de todo o Brasil. Nessa época se instauraram projetos de interiorização e colonização das fronteiras brasileiras, realizadas por meio de ações como a Marcha para Oeste, a construção da rodovia Belém-Brasília, nos anos 1950, e a política de incentivos fiscais da ditadura militar a partir dos anos de 1960 (Martins 1997). Tais episódios ajudaram a desenhar o complexo quadro fundiário no Brasil e movimentaram as fronteiras do país.

Os migrantes motivados pelo desejo de obter acesso à terra, trabalho, moradia ou a busca pela própria sobrevivência e dos seus familiares, encontraram nestas regiões, um jogo de disputa no campo, com atos ilegais de empresários e fazendeiros. No entanto, as famílias que desembarcaram nos 'sertões', e principalmente na região do Baixo Araguaia', possuíram uma voz ativa em defesa de seus direitos, a ilustre pessoa de Dom Pedro Casaldáliga (ESTERCI, 1987).

Para Ferreras (2016, p.413),

A identificação do trabalho forçado e a sua divulgação no Brasil ocorreram a partir da intervenção e da mobilização promovidas pelo padre Pedro Casaldáliga com a sua Carta Pastoral "Uma Igreja da Amazônia em conflito com o latifúndio e a marginalização social", de outubro de 1971, na qual ele associava o regime de trabalho nas fazendas à escravidão. A Carta ganhou

\footnotetext{
${ }^{1}$ A utilização do termo Baixo Araguaia neste trabalho refere-se aos quinze municípios que compõem o Território Cidadania do Baixo Araguaia, constituído pelo Decreto Federal de 25 de fevereiro de 2008, quais sejam: Alto Boa Vista, Bom Jesus do Araguaia, Confresa, Canabrava do Norte, Luciara, Novo Santo Antônio, Porto Alegre do Norte, Querência, Ribeirão Cascalheira, São Félix do Araguaia, São José do Xingu, Santa Cruz do Xingu, Santa Terezinha, Serra Nova Dourada e Vila Rica. Esses mesmos municípios também fazem parte da área de jurisdição da Prelazia de São Félix do Araguaia (DUTRA, 2015).
} 
mais notoriedade quando, no mesmo mês, o padre virou bispo de São Félix do Araguaia.

Dessa forma, Dom Pedro Casaldáliga, em um período crítico da ditadura militar, redigiu a Carta Pastoral com várias denúncias e repudio a escravidão moderna, obtendo repercussões mundiais. No entanto, as ocorrências passaram sistematicamente a ser denunciadas pela Comissão Pastoral da Terra² (CPT) (MARTINS, 2012).

Por meio das Cartas Pastorais as denúncias eram realizadas, descrevendo as condições degradantes dos trabalhadores, e, logo depois, as ocorrências passaram sistematicamente a ser delatadas pela Comissão Pastoral da Terra (CPT, 2016).

Percebe-se que o processo de uso e ocupação do território do Baixo Araguaia foi de grandes conflitos entre de fazendeiros capitalistas e moradores locais. Mas não esperavam que um padre recém-chegado de nome Pedro Casaldáliga fosse contrário ao progresso da monocultura fundiária, contra as injustiças sociais, o trabalho escravo, as impunidades, e em defesa dos posseiros, peões e etnias indígenas e seus territórios, conflitos tais, que permanecem até a atualidade (DUTRA, 2015).

Com certeza, a carta pastoral, atingiu dois problemas raiz, "uma Igreja da Amazônia em conflito com o latifúndio e a marginalização social". É importante ressaltar, que os governos militares desenvolveram programas de ocupação econômica, voltados para grandes empresários com o propósito de explorar, ocupar e obter lucro na Amazônia Legal (LE BRETON, 2002). Com isso, o Estado de Mato Grosso recorreu à expropriação, exploração e expulsão dos povos tradicionais, prática que permanece na atualidade (DUTRA, 2015).

É notória a condição de vulnerabilidade dos trabalhadores campesinos, principalmente vindos do nordeste brasileiro, e que são os alvos prediletos dos aliciadores, que os contratam seguidamente e os submetem a diversas formas de exploração, ou seja, em condições análogas ao de escravo (GUIMARÃES NETO, 2011).

Nesse sentido, Ferreras (2016, p.413) enuncia que:

O modo como um trabalhador ingressa na rede da dívida e do trabalho forçado está vinculado a algumas questões que aparecem simplesmente mencionadas em outros casos: a promessa de um ingresso monetário melhor do que na região da recruta; o mediador entre o trabalhador e o local de trabalho, que tem que ser confiável para quem procura emprego; a possibilidade de retorno

\footnotetext{
2 Nasceu em junho de 1975, durante o Encontro de Bispos e Prelados da Amazônia, convocado pela Conferência Nacional dos Bispos do Brasil (CNBB), realizado em Goiânia (GO). Foi fundada em plena ditadura militar, como resposta à grave situação vivida pelos trabalhadores rurais, posseiros e peões, sobretudo na Amazônia, explorados em seu trabalho, submetidos a condições análogas ao trabalho escravo e expulsos das terras que ocupavam (CPT, 2010).
} 
num prazo adequado. Estas são as condições para alguém ser contratado e entrar na rede de exploração; depois temos que caracterizar os outros elementos necessários para permanecer no local da exploração: a falta de contatos no exterior do local de cativeiro ou dívida; contexto contrário ao trabalhador, como poderia ser uma sociedade organizada para a retenção e o controle dos cativos; a repressão no local e, ainda, a subjetividade do cativo: a honra e o orgulho de ser trabalhador que os obriga a uma dívida excessiva e a um trabalho esmagador, como acontece com os trabalhadores nordestinos nas suas migrações em direção às fronteiras agrárias.

No Brasil, o agronegócio, os empresários e os proprietários de terras têm uma tradição oligárquica na dominação e práticas da violência ao trabalhador. O processo capitalista explora tanto a natureza quanto o ser humano, que fica à mercê do precário atendimento de segurança, saúde e educação. De acordo com Le Breton (2002, p.220), "é importante lembrar que é para gerar lucro que as pessoas são submetidas à escravidão". Dessa forma, homens, mulheres e até crianças são exploradas com o propósito de se obter menor custo de mão-de-obra.

A ocupação da "Amazônia", não deve ser vista apenas levando-se em consideração apenas o fator econômico, mas também o fator geopolítico. Sua ocupação foi realizada adotando-se uma postura em expulsar os povos tradicionais e reduzir demograficamente os espaços das diversas tribos indígenas. Muitos foram os indígenas que migraram para as cidades e se veem em situação de vulnerabilidade social, causando um grande aglomerado de trabalhadores desempregados (MARTINS, 2012).

Le Breton (2002, p. 222) afirma que "nos confins da Amazônia, o Estado é dramaticamente ausente e a pistola é a única lei. Suas vítimas são temporárias e descartáveis". Sob a ótica de abandono ou de "vista grossa" do Estado para com seus habitantes, muitos são os trabalhadores que se tornam vulneráveis às situações impostas no seu cotidiano por indivíduos que detém o controle político e econômico de terras que estão além do poderio estatal, sendo que o contratante oferece ao trabalhador condições precárias de trabalho, propiciando a violação significativa dos direitos dos menos favorecidos.

\section{Trabalho análogo ao escravo}

Ao abordar as condições trabalhistas acima, é necessário firmar o conceito de trabalho análogo ao escravo ${ }^{3}$. Devido sua complexidade, esse artifício não demanda necessariamente

\footnotetext{
${ }^{3}$ A Lei $\mathrm{n}^{\circ} 10.803$, de 11 de dezembro de 2003, altera o artigo 149 do Decreto-lei $\mathrm{n}^{\circ} 2848$ de 07 de dezembro de 1940, e conceitua que o trabalho escravo é "reduzir alguém à condição análoga à de escravo, quer submetendo-o a trabalhos forçados ou a jornada exaustiva, quer sujeitando-o a condições degradantes de trabalho, quer restringindo, por qualquer meio, sua locomoção em razão de dívida contraída com o empregador ou preposto" (BRASIL, 2003). 
que o ser humano seja propriedade de outro, diferentemente da escravidão no Brasil Colônia e Império. Portanto, para se configurar trabalho análogo ao escravo, basta que haja pretensa relação de emprego aos elementos que ferem a dignidade dos cidadãos, degradando-os.

Nesse sentido, Casaldáliga (1971, p. 110) afirma que "agora, a escravidão está mais sofisticada. Tornou-se mais cruel". Dessa maneira, em muitos casos, corre um desrespeito para com os trabalhadores em relação à dignidade humana, pois, na condição de trabalhadores livres, sujeitos de obrigações, de direitos, os remetem para uma condição semelhante à daqueles que viviam em regime de escravidão legitimada em séculos anteriores.

Martins (2012) corrobora com a assertiva de que em seus estudos verifica a existência de vários trabalhos e pesquisas sobre o tema trabalho análogo ao escravo. De acordo com a autora, cada estudo aborda um ponto de vista diferente, tentando definir o que realmente é trabalho análogo ao escravo.

Por outro lado, alguns pesquisadores não querem acreditar que a prática de exploração é reproduzida pelo atual sistema capitalista, "a persistência ou renascimento de formas escravistas de relações de trabalho em diferentes sociedades, põe o pesquisador diante de alguns dilemas de solução difícil" (MARTINS, 2012, p.72). São diversos os confrontos de ideias sobre a definição do tema, principalmente durante a interpretação e análise de legislações.

Os empregadores aderiram à terceirização, como uma técnica frequente e comum em nosso meio, e muitas vezes, podem estar relacionadas diretamente com as práticas do trabalho análogo ao escravo. Nesse sentido, Lima (2002, p. 51), descreve que "o setor privado é o maior agente explorador do trabalho escravo, em escala mundial, onde a agricultura, a construção civil e industrial são os maiores representantes desse segmento".

Cabe destacar que os maiores resgates de trabalhadores em condições análogas à de escravo no Brasil que representa $90 \%$ dos flagrantes, são de trabalhadores terceirizados (WAGNER, 2016). Consequentemente, podemos verificar que esse método ocorre em várias empresas privadas e tem base na exploração do trabalhador para obter lucros exorbitantes.

A Figura 1 apresenta os dados do Ministério Público do Trabalho, referente a trabalhadores libertados em situação de trabalho análogo ao escravo entre os anos de 1995 a 2013.

Figura 1: Número de trabalhadores libertados no Brasil em situação análoga ao trabalho escravo 


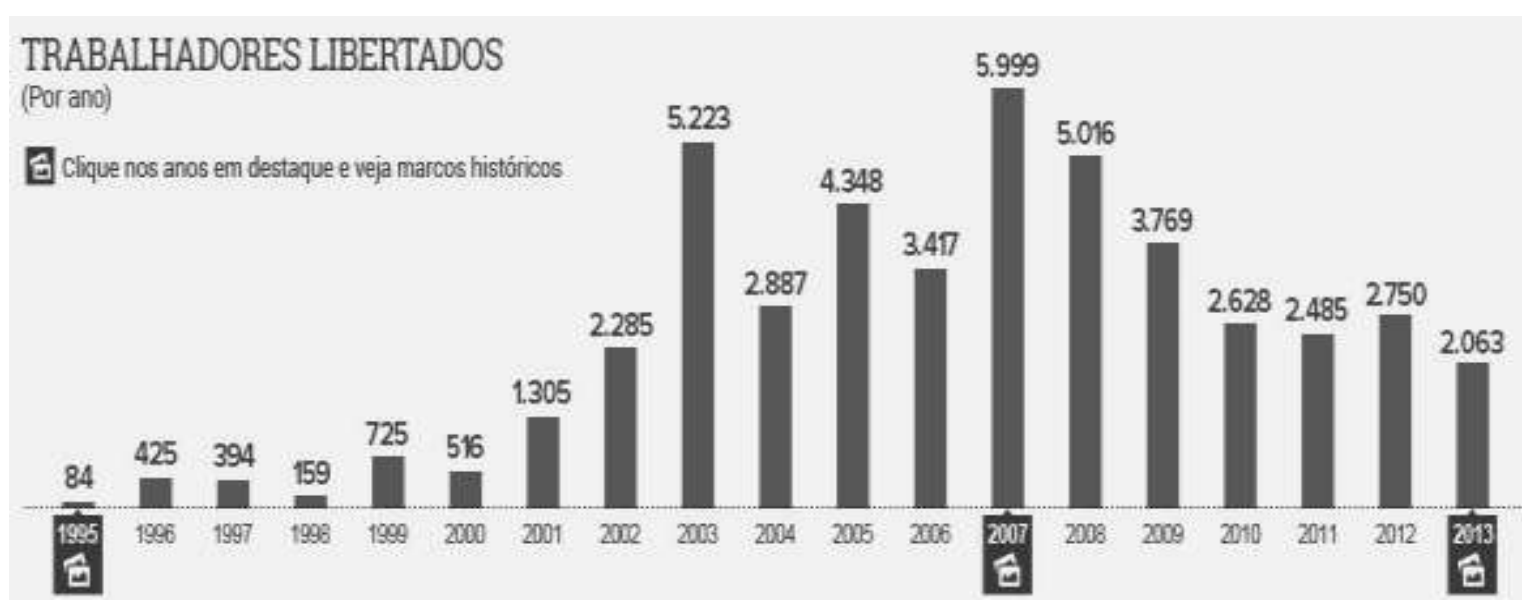

Fonte: Reis (2014).

Em seus estudos, Souza (2016) verifica que os trabalhadores são recrutados fraudulentamente, mediante promessas não cumpridas. Na região do Baixo Araguaia, no final do século XX, essa situação era agravada pela localização das fazendas, que muitas vezes, estava a centenas de quilômetros dos domicílios dos trabalhadores que eram oriundos principalmente das regiões Nordeste e Centro Oeste. A distância era um dos principais problemas enfrentados, pois, muitos trabalhadores chegavam ao local de trabalho de avião ou andavam de carro durante a noite, o que dificultava o reconhecimento do lugar, de tal modo, contrariando as expectativas criadas durante a contratação, e precisamente nestas falsas condições de trabalho é que se encontra o núcleo do aliciamento.

A palavra aliciar diz respeito à ação de aliciar, seduzir, subordinar - oferecer dinheiro em troca de alguma coisa (HOUAISS, 2001). Em forma jurídica, de acordo com o site JusBrasil (2017) aliciar é a "reunião ou a contratação de pessoas para um determinado fim (...) atrair para si com promessas enganosas, enganar, induzir (...) alusão ao artigo 171 do Código Penal Estelionato". Entende-se por esses conceitos que o aliciamento é a mais importante forma de conseguir trabalhadores para prestar serviços na condição análoga a de escravos.

Evidentemente, os patrões e "gatos ${ }^{4 "}$ não revelam aos trabalhadores as verdadeiras condições de trabalho e salário, ao invés, apresentam situações imensamente favoráveis (LE BRETON, 2002). Sabendo dos obstáculos que o trabalhador enfrentará, os "gatos" ludibriam com promessas enganosas no que diz respeito ao salário, alimentação, condições de trabalho e moradia, afrontando os regramentos básicos do direito.

\footnotetext{
${ }^{4}$ Gatos são trabalhadores aliciadores ou empreiteiros que recrutam mão-de-obra e são responsáveis pela administração dos alojamentos, fiscalização, vigilância e transporte dos empregados. Geralmente percorrem vários estados principalmente o Nordeste para contratar trabalhadores (LE BRETON, 2002). 
Na região do Baixo Araguaia, podemos verificar inúmeras situações onde os patrões do campo utilizam-se da alta tecnologia, com colheitadeiras, tratores modernos e novos para obter ganhos altíssimos com suas produções. Por outro lado, os trabalhadores aliciados moram em alojamentos improvisados no meio do mato, sem água potável, alimentação inadequada, sem condições de higiene e segurança e sem possibilidade de deslocamento conforme pode ser visto na Figura 2.

Figura 2: Condições de moradia de trabalhadores em situação análoga ao escravo

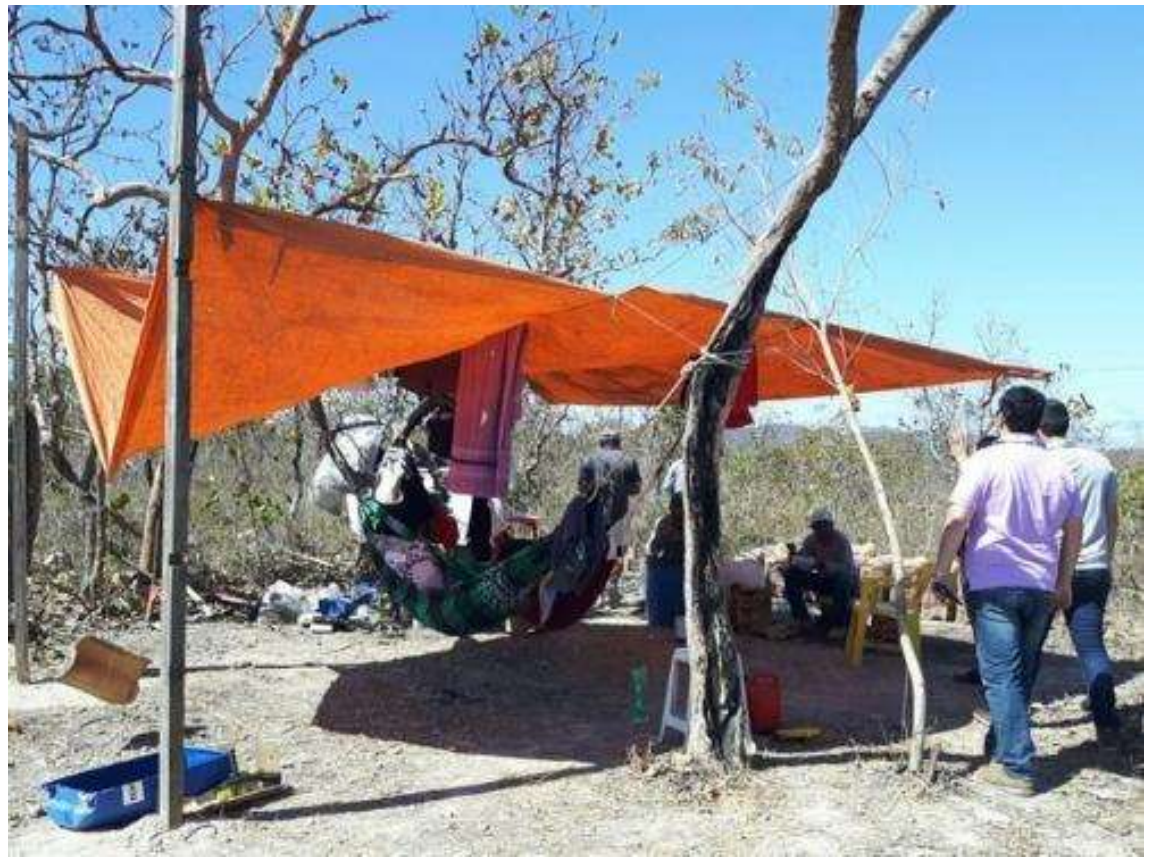

Fonte: Comissão Pastoral da Terra (2017).

Ainda sobre as relações de trabalho, Lima (2002, p.89) expõem que as condições "deixam evidente que o principal objetivo do produtor não é fornecer condições dignas ao seu empregado, mas sim aumentar o seu lucro a qualquer custo".

Esta é uma prática visível da dominação e exploração do trabalhador, em diminuir os custos de produção, garantindo a competitividade no mercado interno e externo, sem a necessidade de redução dos lucros dos proprietários.

Conforme dados coletados pela CPT e o Ministério Público do Trabalho (MPT), os empreendedores que escravizam não são desinformados, pelo contrário, utilizam-se da atual tecnologia moderna, e alguns proprietários vivem bem distantes da região, recebendo informações e direcionando trabalhos a serem realizados (SAKAMOTO, 2015). 
Inúmeras denúncias, dados, depoimentos em diferentes épocas foram registradas pelas autoridades federais, membros da Igreja Católica, CPT, Organização Internacional do Trabalho (OIT), ONG Repórter Brasil e diversos órgãos responsáveis sobre o assunto, no qual se torna imprescindível o valor de discutir, buscar registros, dialogar, questionar e analisar o problema da escravidão contemporânea (MARTINS, 2012).

\section{Trabalhador: oportunidades de emprego e escolaridade}

É gritante que brasileiros, ainda hoje, se tornam escravos. Nesse sentido, Martins (2012, p.93) adverte que atualmente ainda "persiste componentes de relações de trabalho servis do passado, que não foram totalmente abolidas ou superadas. E não foram porque suas condições de reprodução também persistem”. Dentre as principais causas da perpetuação dessa situação podemos citar a marginalização socioeconômica, à adesão ao trabalho em condições temporárias, a desqualificação da mão de obra e a não exigência de grau de escolaridade.

Compreender exatamente o lugar do recrutamento da mão de obra escrava é um desafio. As indicações até o momento obtidas por vários pesquisadores são de trabalhadores vindos de todo o Brasil, embora afirmem que a maioria procede de famílias camponesas em condições vulneráveis do Nordeste.

O pesquisador Martins (2012, p. 92) expõe que "boa parte dos peões que tem trabalhado nas novas fazendas da Amazônia são principalmente jovens que procedem de famílias camponesas do Nordeste e do Centro-Oeste". Esses trabalhadores migram temporariamente por falta de oportunidades de trabalho nos locais de origem, a procura de melhor oportunidade de vida e necessidade de dinheiro, imaginam que essa situação é apenas temporária.

A escravidão é temporária, pois nosso sistema não permite que um cidadão escravize outro, assim que os escravos conseguem escapar das garras dos neo-escravocratas readquirem o status de homens livres. Mas não é por ser temporária que deixa de ser escravidão (MTE, 2017).

A retenção de salários é usada com a finalidade de obrigar os trabalhadores a se submeterem as situações adversas, tais como salários pejorativos e ambientes de trabalho prejudiciais à saúde e à segurança. Os empregadores temem que os trabalhadores, uma vez recebendo seus salários, se desliguem do mau emprego (LE BRETON, 2002).

A servidão por dívida é muito comum e se dá mediante três fatos: salários ínfimos combinados com a venda de mercadorias a preços normais, salários corretos combinados com 
a venda de mercadorias a preços acima do normal, salários ínfimos combinados com a venda de mercadorias a preços altos.

Casaldáliga (1970, p.106) afirma que "iludidos quase sempre a respeito do pagamento, do lugar, das condições de trabalho, do atendimento médico. Tendo que pagar até a viagem contra todo o estipulado num a posteriori decepcionante e forçado". Esses fatores caracterizam a falta de escolaridade do trabalhador, circunstâncias que jamais conseguem pagar seus débitos e, para honrar a palavra, continuam trabalhando.

Na região do Baixo Araguaia a presença da escravidão análoga é intensa, e uma das causas mais comum e preocupante é a baixa escolaridade dos trabalhadores. Muitos são analfabetos, e estes, são os alvos prediletos dos aliciadores. Não tendo escolaridade, o trabalhador tem dificuldade de encontrar um trabalho digno para seu próprio sustento ou da sua família (CPT, 2016).

A fim de verificar se a situação de escolaridade tem influência com o trabalho análogo ao escravo, realizamos uma pesquisa nos processos que se encontram no Ministério do Trabalho e Justiça, localizado no município de Confresa, Mato Grosso. Durante a pesquisa foram encontrados 8 processos, no entanto, em apenas três haviam informações referente ao grau de escolaridade. Os resultados desse estudo encontram-se dispostos no Quadro 1.

Quadro1: Nível de escolaridade dos trabalhadores resgatados entre os anos 2000 a 2007

\begin{tabular}{|c|c|c|c|c|c|c|}
\hline \multirow{2}{*}{$\begin{array}{l}\text { Fazenda e } \\
\text { localidade }\end{array}$} & \multirow{2}{*}{$\begin{array}{l}\text { Número de } \\
\text { trabalha- } \\
\text { dores }\end{array}$} & \multicolumn{4}{|c|}{ Nível de escolaridade dos trabalhadores resgatados } & \multirow{2}{*}{$\begin{array}{c}\text { Trabalhadores } \\
\text { em condição } \\
\text { análoga ao } \\
\text { escravo }\end{array}$} \\
\hline & & $\begin{array}{c}\text { Analfabeto } \\
\mathrm{s}\end{array}$ & $\begin{array}{c}\text { Semi- } \\
\text { Analfabetos }\end{array}$ & $\begin{array}{l}\text { Ensino } \\
\text { Médio }\end{array}$ & $\begin{array}{c}\text { Não } \\
\text { informou }\end{array}$ & \\
\hline $\begin{array}{l}\text { FazendaRio Preto } \\
\text { Canabrava do Norte }\end{array}$ & 271 & 06 & 07 & & 05 & 18 \\
\hline $\begin{array}{l}\text { Fazenda Inajá } \\
\text { São José do Xingu }\end{array}$ & 16 & 01 & 03 & & & 04 \\
\hline $\begin{array}{l}\text { Fazenda Guariba } \\
\text { Vila Rica }\end{array}$ & 150 & 29 & 49 & 02 & 47 & 127 \\
\hline
\end{tabular}

Fonte: Dados coletados no Ministério do Trabalho e Justiça em Confresa- MT, por Susana Ferreira da Silva, 2017.

Cabe destacar que a pesquisa foi realizada em processos que estão arquivados, bem como em processos suspensos (processos em que foram firmados TACs e aguardam cumprimento do mesmo), ou seja, casos de atos análogos à escravidão que ocorreram entre os anos de 2000 a 2007 e que foram julgados ou que tiveram os Termos de Ajustamento de 
Conduta cumpridos. Também foi possível verificar que muitos empregadores não cumprem o Acordo Judicial ou Termo de Ajustamento de Conduta nos termos estabelecidos perante o Ministério do Trabalho e Emprego e como os processos aguardam o cumprimento do ajustado em escaninho próprio (local designado para receber processos pendentes), sendo que tal sistemática dificulta o acesso aos processos.

Como o marco temporal da pesquisa é do ano de 2000 a 2017, nesse caso, foram encontrados apenas três casos na região do Baixo Araguaia, nos municípios de Canabrava do Norte, São José do Xingu e Vila Rica. Outro fator que dificultou o acesso aos processos é o fato da maioria ainda não ser digitalizada, nesses casos foi necessário analisar todas as páginas, bem como identificar as informações mais relevantes. O principal objetivo foi saber a escolaridade do trabalhador que foi submetido ao trabalho análogo ao escravo.

Considerando relevante a análise do problema da escravidão contemporânea e as diversas denominações para essa prática, torna-se necessário compreender as designações do campo político e social, sendo que Esterci (1987, p. 140) expressa que "as formas de exploração do trabalho não ocorrem com a mesma configuração, mas cada caso tem as suas peculiaridades".

Assim sendo, devemos prosseguir com as pesquisas e discussões a fim de definir conceitualmente e juridicamente o termo trabalho análogo ao escravo contemporâneo, para que este não seja banalizado pelos governantes e empregadores, que insistem em desvalorizar e desrespeitar o trabalhador.

\section{Considerações finais}

Desde a chegada dos colonizadores portugueses o Brasil enfrenta esse problema que é a escravidão de pessoas. Com isso estruturando uma postura latifundiária, agregando a escravidão como base para a manutenção de um regime trabalhista que exigia a força braçal para a extração de bens de consumo e mercadorias para suprir aos anseios mercantilistas da Metrópole.

A luta pela liberdade foi constante no Brasil escravocrata, pois desde que foram feitos escravos, índios e negros lutaram contra suas amarras. No entanto, o processo abolicionista brasileiro deu margem à continuidade das desigualdades. As senzalas foram abertas, porém, após esse momento, a liberdade significou a luta pela sobrevivência. Não houve equiparação social no Brasil, todavia, o fortalecimento das desigualdades em um Estado que logo nasceria republicano. 
Novas fronteiras agrícolas foram desbravadas no século XX, mas ainda assim, o poder dos latifundiários se fez presente. Famílias se deslocaram em busca de empregos e oportunidades de uma vida melhor. Todavia, quanto mais ao oeste, menor era o poderio do Estado. Hoje, o agronegócio é uma realidade. As terras conquistadas tornaram-se em grande parte, propriedade de fazendeiros que não contradizem a herança brasileira do latifúndio. A escravidão moderna persiste. O trabalho análogo ao escravo é uma verdade no Brasil contemporâneo.

Relatar o trabalho análogo a escravidão na região do Baixo Araguaia é necessária. Mais do que nunca, é preciso expor as condições humilhantes aos quais trabalhadores advindos de várias regiões do Brasil são submetidos ao encontrar um 'emprego' que poderia dar-lhe uma ascensão financeira, e que, infelizmente, os reduz a situações análogas ao trabalho escrevo.

Na região, são diversas as irregularidades, dentre essas, infrações cometidas à legislação trabalhista, principalmente os direitos mínimos dos trabalhadores, consistentes em normas de segurança e higiene do trabalho, inclusive no que tange ao pagamento de salários e condições humanas aos trabalhadores. Também o crescimento da dívida do trabalhador com a propriedade em desproporção ao quantum salarial caracteriza a escravidão por endividamento, forma contemporânea de reduzir o homem à condição análogo a de escravo.

Outro aspecto importantíssimo a ser considerado, é a falta de acesso à educação que esses brasileiros tiveram, pois conforme os registros da CPT, dados da OIT e a pesquisa realizada confirmam que a maioria das pessoas libertadas possui pouco ou nenhum nível de escolarização. Percebe-se que a ausência ou a baixa escolaridade pode ser considerada uma das principais causas do tipo de trabalho análogo ao escravo, pois é um elemento que está presente na maioria das ocorrências dessa situação no Brasil e região do Baixo Araguaia.

Infelizmente, no Brasil nos dias atuais, muitos trabalhadores em suas consciências, e em razão da idoneidade moral, mesmo não sofrendo e qualquer ameaça, admitem, muitas vezes por falta de informação, serem submetidos ao trabalho análogo ao escravo. Isto demonstra que o trabalhador brasileiro, além de ser cônscio de seus deveres morais, é facilmente manipulado e escravizado pelo empregador, e este tem certeza da sua impunidade. Logo, mais do que nunca é preciso resistir, denunciar, construir alternativas reais, e enfrentar esse problema social que ainda ocorre em pleno século XXI na sociedade brasileira

\section{Referências}

ALONSO, Angela. O Abolicionismo como movimento social. São Paulo: Novos Estudos 100, nov. 2014. p. 115-137. 
BOBBIO, N. Teoria geral da política: a filosofia política e as lições dos clássicos. Tradução de Daniela B. Versiani. Rio de Janeiro: Campus, 2000.

BRASIL. Decreto lei n ${ }^{\circ} 2848$, de 7 de dezembro de 1940. Código Penal. Disponível em: http://www.planalto.gov.br/ccivil_03/decreto-lei/Del2848.htm. Acesso em18 mar.2016.

Lei n 10.803 de 11 de dezembro de 2003. Disponível em:

<http://www.planalto.gov.br/ccivil_03/leis/2003/L10.803.htm>. Acesso em: 15 jan. 2017.

REIS, Thiago. Histórico da Comissão Pastoral da terra. 2014. Disponível em:

<http://g1.globo.com/economia/trabalho-escravo-2014/platb/z. Acesso em: 05 ago. 2017.

CARDOSO, Ciro Flamarion. Escravidão antiga e moderna. Rio de Janeiro: Tempo, v. 3, n. 6, dez. 1998.

CASALDÁliGA, Pedro. Uma Igreja da Amazônia em conflito com o latifúndio e a marginalização social. 1971. Disponível em:

<http://www.servicioskoinonia.org/Casaldaliga/cartas/1971CartaPastoral.pdf>. Acesso em: 09 set. 2013.

COTRIM, Gilberto. História global: Brasil e geral. Volume Único. 3. ed. Saraiva: São Paulo, 1998.

CPT - Comissão Pastoral da Terra. Conflitos no Campo:Brasil 2016 [Coordenação Canuto, Cássia Regina da Silva Luz, Thiago Valentim Pinto Andrade - Goiânia]: CPT Nacional Brasil, 2016. p. 232.

. Comissão Pastoral da Terra. Cadernos Conflitos no Campo: todos os números entre 2003 a 2007. CPT - Loyola 2003-2007.

Comissão Pastoral da Terra. Histórico. 2010. Disponível em:

<https://www.cptnacional.org.br/quem-somos/-historico>. Acesso em: 09set.2016.

DOURADO, Maiara. A luta de Trombas e Formoso: uma ruptura narrativa no contexto da ditadura militar. São Paulo: Campos, v. 2, n. 15, p. 99-120, 2014.

DUTRA, Mara Maria. Formação em agronomia no IFMT Campus Confresa e sua relação com a sustentabilidade na agricultura familiar no contexto do território cidadania do Baixo Araguaia. 2015. 148 f. Dissertação (Mestrado em Ciências Ambientais) - Programa de Pós-Graduação em Ciências Ambientais, Universidade do Estado de Mato Grosso, UNEMAT. Cáceres, Mato Grosso, Brasil, 2015

ESTERCI, Neide. Conflitos no Araguaia: peões e posseiros contra a grande empresa. Petrópolis: Vozes, 1987.

FAUSTO, Boris. História do Brasil. Brasília: Ministério da Educação, Secretaria de Educação a Distância, 2002. 128 p. 
FERRERAS, Noberto O. O Brasil e o trabalho análogo à escravidão. Revista do Arquivo Geral do Rio de Janeiro, n. 11, 2016, p. 407-422.

GIL, Antonio Carlos. Como elaborar projetos de pesquisa. 5. ed. São Paulo: Atlas, 2010.

GUIMARÃES NETO, Regina B. História, política e testemunho: violência e trabalho na Amazônia brasileira. A narrativa oral da presidenta do Sindicato dos Trabalhadores Rurais de Confresa (MT). História Oral, v. 13, n. 1, jan.-jun. 2010. p. 53-58.

HOUSSAIS, Antônio. Dicionário Houaiss da Língua Portuguesa. Rio de. Janeiro: Objetiva, 2001.

JUSBRASIL. Disponível em: <https://www.jusbrasil.com.br/topicos/294214/aliciar>. Acesso em: out. 2017.

LE BRETON, Binka. Vidas Roubadas: a escravidão moderna na Amazônia brasileira. São Paulo: Loyola, 2002.

LIMA, Maria do Rosário Soares. Porto Alegre do Norte: uma história de luta e resistência. Monografia de graduação, UNEMAT, 2002.

MARTINS, José de Souza. Fronteira: a degradação do outro nos confins do humano. 2. ed. São Paulo: Contexto, 2012.

MONTEIRO, Patrícia Fontes C. Discussão acerca da eficácia da Lei Áurea. Meritum. Belo Horizonte, v.7, n.1, jan.jun. 2012.p. 355-387.

MOTA, Myriam Becho; BRAICK, Patrícia Ramos. História: das cavernas ao terceiro milênio. 1. ed. São Paulo: Moderna, 1997.

Ministério do Trabalho e Emprego. Plano Nacional Para a Erradicação do Trabalho Escravo. 2003. Disponível em: <http://www.ilo.org/brasilia/lang--pt/index.htm >. Acesso em: 05 jun. 2017.

NETO, Manuel Pacheco. A escravização indígena e o bandeirante no Brasil colonial: conflitos, apresamentos e mitos. Dourados MT: Editora UFGD, 2015.

OLIVEIRA, Ariovaldo Umbelino. Modo de produção capitalista, agricultura e reforma agrária. São Paulo: Labur Edições, 2007, 184 p.

PESSOA, Jadir de Morais. A Revanche camponesa. Goiânia: Editora da UFG,1999.

RIBEIRO, Darcy. O povo brasileiro: a formação e o sentido do Brasil. 2. ed. São Paulo Companhia das Letras, 1995.

RODRIGUES, Raymundo Nina. Os Africanos no Brasil. Rio de Janeiro: SciELO Livros, 2010 . 
RUA, M. das G. Análise de políticas públicas: conceitos básicos. 1997. Disponível em: <http://franciscoqueiroz.com.br/portal/phocadownload/gestao/rua\%20maria\%20_\%20analise depoliticaspublicas.pdf > . Acesso em: 20 dez. 2016.

SAKAMOTO, Leonardo (coord.). Trabalho escravo no Brasil do Século XXI. Brasília, OIT, 2015).

SILVA, Tomaz Tadeu; HALL, Stuart; WOODWARD, Kathryn. Identidade e Diferença: a Perspectiva dos Estudos Culturais. Tradução Tomaz Tadeu da Silva. Petrópolis: Vozes, 2000.

SOUZA, Maria Aparecida Martins. Escravidão Contemporânea nas Agropecuárias do Araguaia (1970-2005). In: Araguaia: o (des)encontro de diferentes agentes sociais / João Carlos Barrozo (org.). Cuiabá: EdUFMT, 2016. p. 69-102.

VOLPATO, Luíza. Entradas e bandeiras. 3. ed. São Paulo: Global, 1985.

WAGNER, Alfredo. As ocorrências de trabalho escravo relativizam a visão triunfalista da chamada "modernização da agricultura" p.134-140. In: CPT - Comissão Pastoral da Terra. Conflitos no Campo - Brasil 2016 [Coord. CANUTO; LUZ, Cássia Regina da Silva, ANDRADE, Thiago Valentim Pinto - Goiânia]: CPT Nacional - Brasil, 2016. 